optic nervehead was treated by endolaser photocoagulation intraoperatively. The retina was completely attached postoperatively. Visual acuity improved to $0 \cdot 1$.

\section{Comment}

Congenital optic nervehead coloboma is believed to reflect defective closure of the embryonic fissure. ${ }^{5}$ Our patient showed a unilateral coloboma inferior of the optic nervehead that was continuous with a small choroidal coloboma. Thus, it is very likely that the embryonic fissure had closed incompletely at an early gestational stage.

We observed a condensed Cloquet's canal that terminated at the membrane covering the central depression of the optic nervehead. A normal Cloquet's canal, which contains the vestiges of primary vitreous, is a tubular structure crossing the vitreous body anteroposteriorly and ending around the optic nervehead margin. ${ }^{6}$ Since the embryonic fissure permits mesodermal tissue to enter the optic cup at an early gestational stage to form a hyaloid artery and primary vitreous, ${ }^{57}$ the anomalous Cloquet's canal, which contains hyperplastic primary vitreous, may terminate at the fine membrane that covers the central depression of the optic nervehead. Thus, we believe that eyes with optic nervehead coloboma may have congenital malformation of the vitreous body and an optic nervehead anomaly.

Our case showed clinical characteristics in keeping with morning glory syndrome, since it is thought to be a specific type of optic nervehead coloboma. ${ }^{8}$ A rhegmatogenous retinal detachment has been observed in some cases of morning glory syndrome. ${ }^{-11}$ Morning glory syndrome also has been reported associated with persistent hyperplastic primary vitreous. ${ }^{12}{ }^{13}$ Thus, our case may illustrate that optic nervehead coloboma and morning glory syndrome are part of the spectrum of congenital optic nervehead anomalies associ- ated with a defective closure of embryonic fissure.

The influence of an anomalous Cloquet's canal on developing retinal detachment is uncertain. Cooling and Feretis ${ }^{14}$ noted the role of vitreoretinal attachment in the genesis of retinal detachment associated with choroidoretinal coloboma. Harris et al ${ }^{11}$ reported a case of extensive rhegmatogenous retinal detachment complicating morning glory syndrome in which a tiny peripapillary retinal break with adjacent vitreous traction was found. Our case showed a tiny retinal break near the optic nervehead and whiplash motion of the anomalous Cloquet's canal. Thus, we speculate that in our case anteroposterior traction on the adjacent retina caused by the whiplash motion of the anomalous Cloquet's canal at the moment of injury may contribute to retinal break formation and subsequent rhegmatogenous retinal detachment.

1 Michels RG, Wilkinson CP, Rice TA. Retinal detachment. St Louis: Mosby, 1990: 152-3.

2 Sugar HS. Congenital pits in the optic disc and their equivalents (congenital colobomas and colobomalike excavations) lents (congenital colobomas and colobomalike excavations) 298-307.

3 Hamada S, Ellsworth RM. Congenital retinal detachment and the optic disk anomaly. Am $\mathcal{F}$ Ophthalmol 1971; 71: 460-4. 4 Savell J, Cook JR. Optic nerve colobomas of autosomaldominant heredity. Arch Ophthalmol 1976; 94: 395-400.

5 Mann I. Developmental anomalies of the eye. 2nd ed. London: British Medical Association, 1957: 113-6.

6 Tolentino FI, Schepens CL, Freeman HM. Vitreoretinal disorders. Philadelphia: Saunders, 1976: 13

7 Sebag J. The vitreous. New York: Springer Verlag, 1989: 8-16.

8 Apple DJ, Rabb MF Walsh PM Congenital anomalies of the optic disc. Surv Ophthalmol 1982; 27: 3-41.

9 von Fricken MA, Dhungel R. Retinal detachment in the morning glory syndrome. Retina 1984; 4: 97-9.

10 Akiyama K, Azuma N, Hida T, Uemura Y. Retinal detach ment in morning glory syndrome. Ophthalmic Surg 1984; 15: 841-3.

11 Harris MJ, De Bustros S, Michels RG, Joondeph HC. Treatment of combined traction-rhegmatogenous retinal detachment in the morning glory syndrome. Retina $1984 ; 4$ 249-52.

12 Steinkuller PG. The morning glory disk anomaly: case report and literature review. F Pediatr Ophihalmol Strabismus 1980 17: 81-7.

13 Beyer WB, Quencer RM, Osher RH. Morning glory syndrome. Ophthalmology 1982; 89: 1362-7.

14 Cooling RJ, Feretis EB. Retinal detachment and choroidoretinal coloboma. S Afr Arch Ophthalmol 1983; 10: 9-18.

\title{
Neurocytoma of the retina
}

\author{
Cecily Metcalf, Edward M Mele, Ian McAllister
}

Department of

Pathology, Royal Perth

Hospital

C Metcalf

Department of

Ophthalmology, Royal

Perth Hospital

E M Mele

I McAllister

Correspondence to:

C Metcalf, Department of

Pathology, Royal Perth

Hospital, Box X2213 GPO

Perth, WA 6001, Australia.

Accepted for publication

26 January 1993
Neurocytomas are neoplasms with evidence of neuritic differentiation. Most do not appear to have malignant potential. They are rare and all have been found in the lateral or third ventricles of the brain. To our knowledge, a neurocytoma has not previously been described in the retina.

\section{Case report}

A 67-year-old man presented in April 1991 to the emergency room of a local hospital with acute visual loss in his left eye. A superior temporal retinal detachment with a moderate vitreous haemorrhage was noted on funduscopy. In addition a white elevated lesion was noted on the inferior aspect of the attached retina.

The patient underwent a scleral buckle the following day. Postoperatively a total retinal detachment with an increase in the vitreous haemorrhage was noted and the patient was transferred to our care. Examination confirmed the presence of a total retinal detachment except 
Figure 1 Photomontage of posterior fundus of left eye showing a creamy-white flocculated lesion below the infratemporal vascular arcade. (Magnification $\times 4$.)

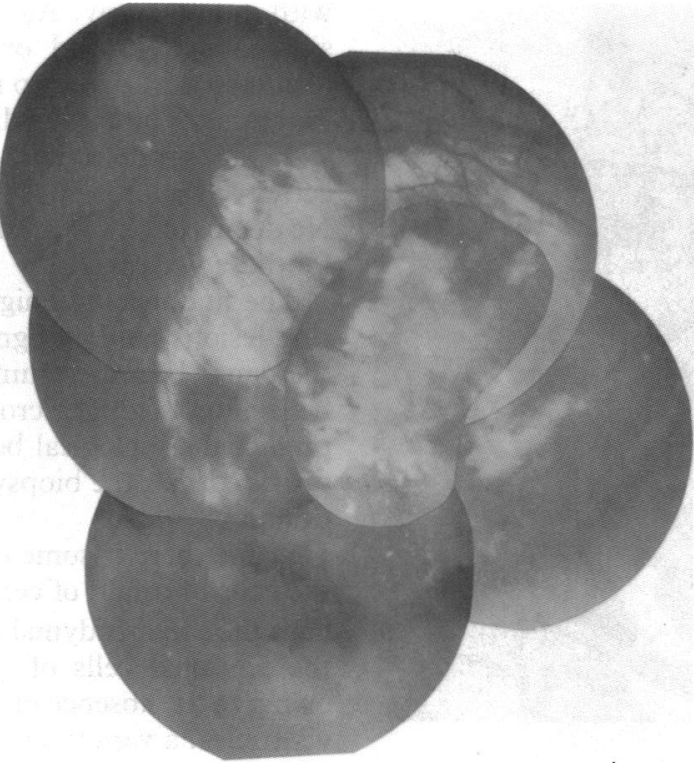

in the area of the white lesion. Several large open posterior breaks were seen and a moderate vitreous haemorrhage was present. The patient had no history of any ocular disorder and his family history was unremarkable. Examination of the right eye was normal apart from the presence of asteroid hyalosis.

The patient underwent a vitrectomy, revision of his scleral buckle and gas fluid exchange with successful reattachment of his retina. During the procedure a three disc diameter creamy-white flocculated lesion with granules suggestive of calcification was noted below the inferior temporal vascular arcade (Fig 1). The retina surrounding the lesion was attached to the choroid by an atrophic scar. Approximately one third of the lesion was excised with intraocular scissors for histological examination.

Light microscopic examination of the biopsy specimen showed several fragments of tissue composed of sheets of cells with round, regular nuclei exhibiting finely granular chromatin. The cytoplasmic borders were ill defined but abundant eosinophilic fibrillary material could be seen between the nuclei (Fig 2). Mitoses were not apparent. Calcified particles were noted within the tissue fragments (Fig 3). Necrosis was not present. Immunohistochemical stains revealed labelling of the cells by neuron specific enolase (NSE), but not by glial fibrillary acidic protein (GFAP). A diagnosis of retinocytoma ${ }^{1}$ was made.

Electron microscopy demonstrated well developed features of neuritic differentiation

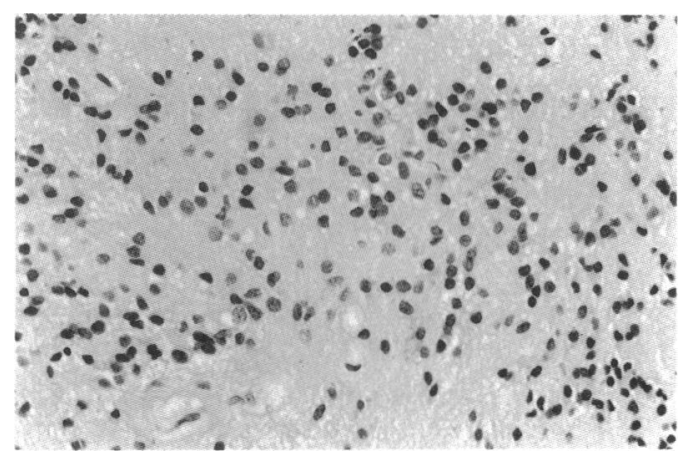

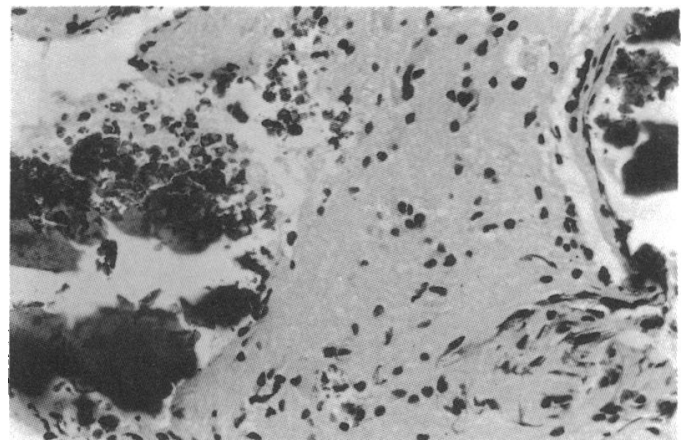

Figure 3 Several large fragmented deposits of calcification. (Haematoxylin andeosin, magnification $\times 130$.)

incuding numerous long, slender, interdigitating cell processes filled with microtubules (Fig 4). Intermediate cell junctions were readily found and a few were elongated, resembling primitive synapses. Golgi complexes, mitochondria, and ribosomes were seen in the cytoplasm, but neurosecretory granules were not identified (Fig 5). There was no evidence of photoreceptor differentiation and this fact, along with the presence of neuritic differentiation indicated a neurocytoma ${ }^{2}$ rather than a retinocytoma.

\section{Comment}

The retinal lesion was initially called a retinocytoma on histological grounds, in spite of the absence of fleurettes which are a feature of retinocytomas. The tumour appeared benign with cells separated by abundant, fibrillary intercellular matrix. The nuclei exhibited finely granular chromatin and mitoses and necrosis were not seen. The clinical appearance was also consistent with a retinocytoma since retinocytomas occur as placoid masses with calcification. Neurocytomas and retinocytomas have similar histological features including well spaced bland cells, a fibrillary background, calcification, and immunoreactivity to NSE. However, fleurettes are seen in retinocytomas and in the few cases $^{1}$ studied by electron microscopy, evidence of photoreceptor differentiation was readily demonstrated. Therefore, a lesion which is clearly benign and lacks fleurettes by light microscopy and which demonstrates neuritic differentiation but no photoreceptor differentiation by electron microscopy can be considered a neurocytoma.

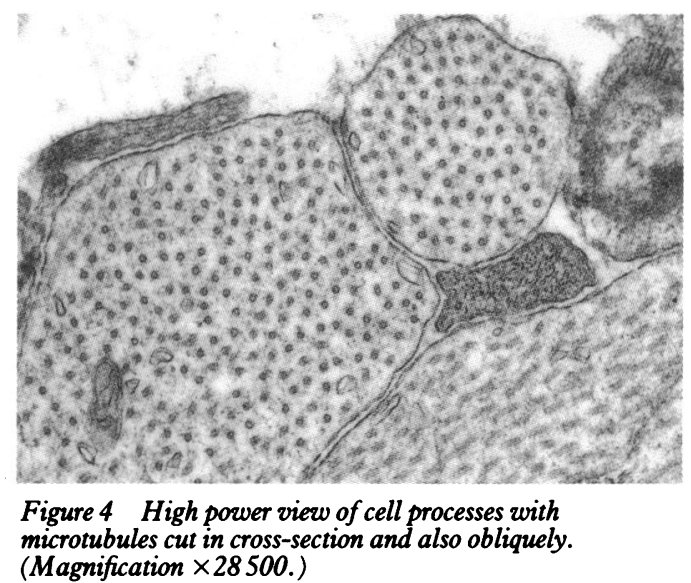




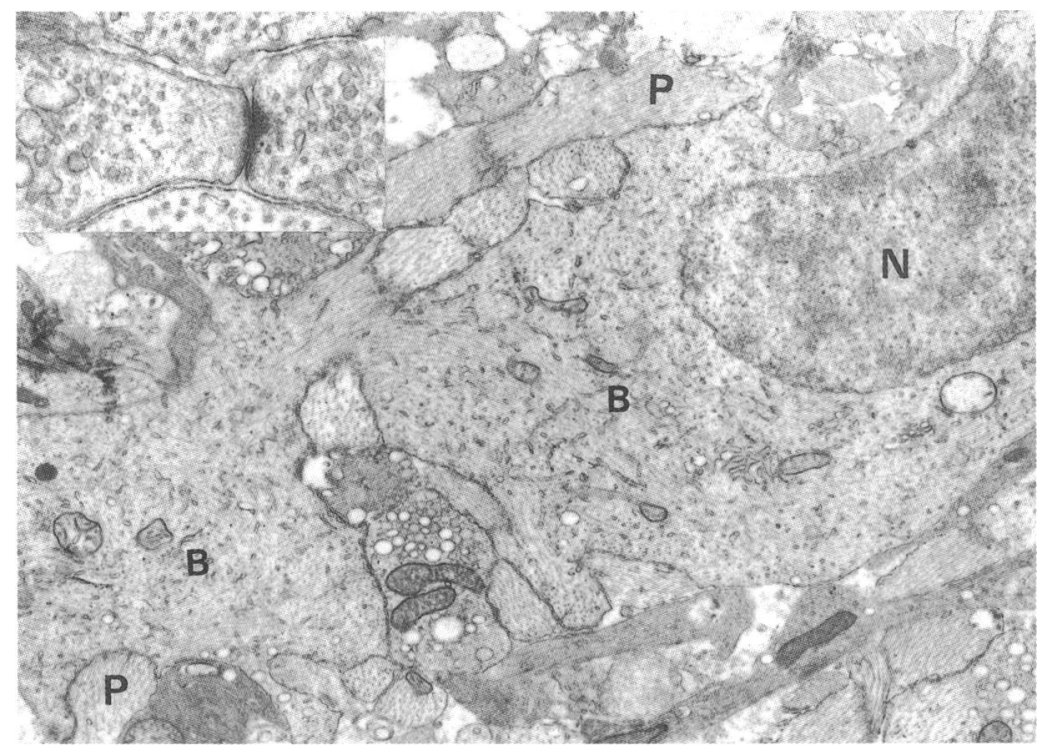

Figure 5 Tumour cell with nucleus $(N)$ and an irregular elongated cell body $(B)$ containing microtubules, Golgi complexes, and mitochondria. Numerous cell processes $(P)$ are seen adjacent to the cell body. Inset: a junction between two cell processes, resembling a synapse. (Magnification $\times 7375$, inset magnification $\times 26500$.)
Forty four cases of neurocytoma have been documented in the literature. Barbosa et $a l^{2}$ reported three cases and reviewed a further 17 cases, and 11 cases were found in a retrospective survey of periventricular tumours. ${ }^{3}$ The remainder consist of mainly single case reports. All have been found in the lateral and/or third ventricles of the brain and the pathological diagnosis required electron microscopy or immunohistochemistry. The tumours had a relatively consistent appearance by light microscopy with some resemblance to oligodendrogliomas or ependymomas. Most tumours subjected to immunohistochemistry reacted to synaptophysin (a marker of neuroendocrine cells) and to NSE (a marker of neuronal and glial cells). Some tumours showed immunoreactivity to GFAP (an intermediate filament found in glial cells) but most of the reactive cells were considered to be non-neoplastic astrocytes. Electron microscopy demonstrated a range of changes. Neurosecretory granules were absent or present in varying numbers. Synapses were also absent, poorly formed, or well formed. Microtubules varied in number from a few to many. However, all had numerous cell processes. The lesions occurred predominantly in young adults (age range 15-53 years) and affected both genders equally. Most lesions were totally or subtotally excised and more than one third were also treated with radiotherapy. All but two cases were considered benign and only one recurrence was documented (follow up ranges from 3 months to 18 years). The two malignant lesions exhibited vascular proliferation, necrosis, and mitotic activity, ${ }^{3}$ features not seen in the benign lesions. No details of follow up or outcome were available for these two cases.

The findings of benign lesions, benign recurring lesions, and malignant lesions suggest that there may be a spectrum of degrees of biological behaviour; light microscopy may be able to predict the biological behaviour of the tumour, provided that the biopsy is representative of the tumour.

While there is some difficulty in determining the cells of origin of central neurocytomas (perhaps the subependymal plate of the ventricles, or the neuronal cells of the septum pellucidum) owing to the absence of neuronal cells within the ventricles, a variety of neurons are found in the retina apart from the photoreceptor cells, and any one of these may represent the cell of origin in the retinal neurocytoma.

Since electron microscopy is usually needed to make a definitive diagnosis of neurocytoma, it is likely that some lesions labelled 'retinocytomas' are in fact neurocytomas, especially since many are diagnosed on clinical grounds alone. Similarly the three oligodendrogliomas that have been described in the retina, ${ }^{4}$ may be neurocytomas since many neurocytomas resemble oligodendrogliomas by light microscopy, and since oligodendrocytes are not normally present in the retina.

It is important to differentiate between a retinocytoma and a neurocytoma since retinocytomas may be a manifestation of the retinoblastoma gene, particularly if found in the setting of a spontaneously regressed retinoblastoma.

We wish to thank Professor J Papadimitriou for his assistance with the electron microscopy.

1 Margo C, Hidayat A, Kopelman J, Zimmerman L. Retinocytoma, a benign variant of retinoblastoma. Arch Ophthalmol cytoma, a benign varia

2 Barbosa MD, Balsitis $M$, Jaspan T, Lowe J. Intraventricular neurocytoma: a clinical and pathological study of three cases and review of the literature. Neurosurgery 1990; 26: 1045-54.

3 von Deimling A, Janzer R, Kleihues P, Wiestler OD. Pattern of differentiation in central neurocytoma, an immunohistochemical study of eleven biopsies. Acta Neuropathol 1990; 79, 473-9.

4 Boniuk M, Bishop D. Oligodendroglioma of the retina. Suro Ophthalmol 1969; 13: 284-9. 